\title{
Wie Diabetes der Haut zusetzt
}

\begin{abstract}
Viele, vor allem ältere Diabetiker können sich in ihrer Haut nicht mehr wohlfühlen. Das Spektrum der dermatologischen Probleme reicht von der trockenen, juckenden Haut über Infektionen und spezifische, diabetesbedingte Hauterkrankungen bis hin zu dermatologischen Nebenwirkungen der Antidiabetika.
\end{abstract}

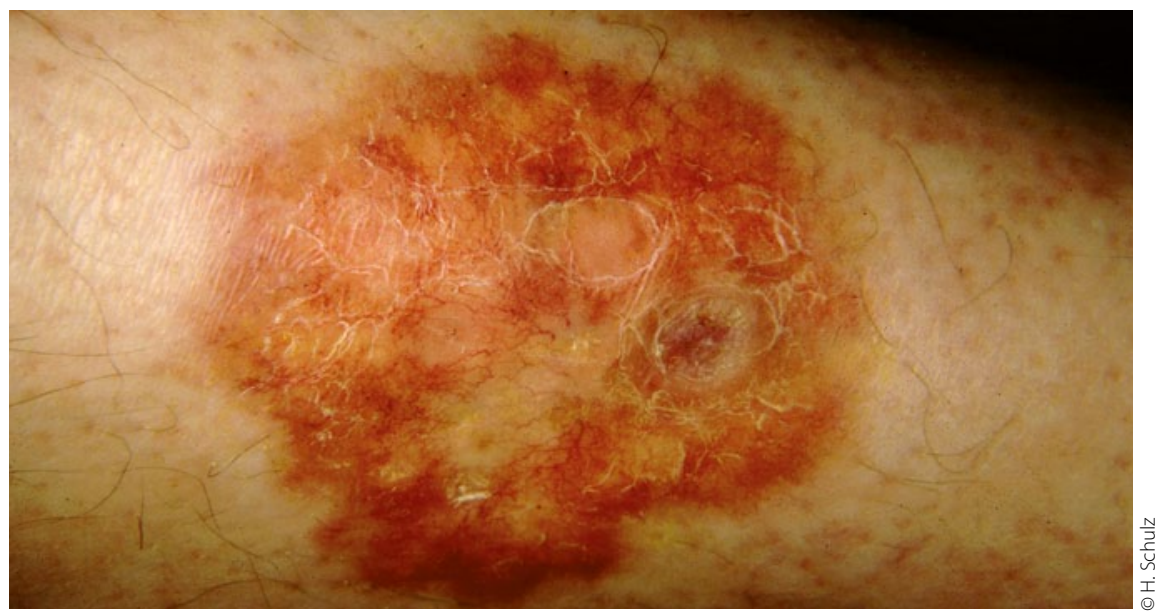

Necrobiosis lipoidica auf dem Unterschenkel einer Diabetikerin.

— Bei bis zu 70\% aller Diabetiker finden sich krankhafte Hautveränderungen, sagte Dr. Alexander Friedl, Leiter des Geriatriezentrums Stuttgart. Nicht selten manifestieren sie sich bereits im Stadium des Prä-Diabetes.

\section{Veränderte Diabetikerhaut}

Die Pathomechanismen, die zu den Hauterkrankungen bei Diabetikern führen, sind vielfältig: Gestört sind sowohl die zellvermittelte Immunabwehr als auch die Hautinnervation und die Durchblutung infolge der Makro- und Mikroangiopathie. Zudem finden sich Veränderungen im Bereich der extrazellulären Matrix. Dies alles führt zu einer Störung der Wundheilung, zu einer Veränderung des Wassergehalts der Haut und der Elastizität. Auch die Expression proinflammatorischer Gene und entsprechender Transkriptionsfaktoren dürfte beteiligt sein. „Typisch für die Haut bei Diabetikern ist die Verdickung der Basalmembran und die veränderte Elastizität der Gefäßwände“, so Friedl.

\section{Gestörte Schweißbildung führt zur Austrocknung}

Das häufigste dermatologische Problem v. a. bei älteren Diabetikern ist die trockene Haut mit Juckreiz. Bei Diabetikern ist sowohl die Hautfeuchtigkeit als auch der Fettgehalt der Haut und die Talgproduktion vermindert. Dazu kommt die diabetische Neuropathie, die wiederum zu einer Störung der Mikrozirkulation und zu einer gestörten Regulation der Schweißdrüsenaktivität führt. Die trockene Haut beim Diabetiker entsteht vorrangig durch die fehlende Kühlfunktion des Schweißes mit konsekutiver Überwärmung der Haut im Sinne einer globalen Anhidrose. Bei ausgeprägten Fällen spricht man von Exsikkationsekzem bzw. Dermatitis sicca.

\section{Quälender Juckreiz}

Entscheidend für die Entstehung des oft quälenden Juckreizes ist die subtile Reizung der Schmerzrezeptoren in der Haut durch diabetesbedingte Stoffwechselprodukte. Besonders ausgeprägt ist der Juckreiz bei Vorliegen einer diabetischen Nephropathie.

Eine diabetestypische Hauterkrankung ist die Prurigo simplex subacuta. Hierbei finden sich stark juckende entzündliche Papeln, wobei nach Aufkratzen der Juckreiz meist rasch sistiert. Ursache ist eine allergische Reaktion.

\section{Breites Spektrum an Hauterkrankungen}

Das Spektrum diabetesbedingter bzw. diabetesassoziierter Hauterkrankungen reicht von der Vitiligo über den Pseudoikterus mit Gelbverfärbung der Haut und/oder der Nägel (Aurantiasis cutis) und die Purpura diabeticorum bis hin zur Bullosis diabeticorum, die mit Blasenbildung einhergeht, und zur Necrobiosis lipoidica (s. Abb.).

Eine weitere Komplikation ist die Lipohypertrophie bei insulinpflichtigen Diabetikern. Die Injektion in solche hypertrophierten Fettgewebsareale beeinträchtigt die Insulinwirkung und erschwert die Stoffwechseleinstellung. Deshalb sollte man gerade bei älteren Patienten solche Hautareale mit einem Farbstift markieren, um die richtige Insulinapplikation zu erleichtern.

\section{Grundregeln der Hautpflege}

Grundsätzlich empfiehlt sich, die Haut zweimal täglich einzucremen. Bei sehr trockener Haut sollten Harnstoffpräparate verwendet werden. Bei starkem Juckreiz ist evtl. auch ein topisches Glukokortikoid indiziert. Sinnvoll sind rückfettende Bäder, wobei milde, $\mathrm{pH}$ neutrale Substanzen eingesetzt werden sollten. „Diabetiker sollten nicht länger als fünf bis zehn Minuten baden, da ansonsten die Haut weiter austrocknet", so Friedl. Hautfalten sollten gut getrocknet werden, da feuchte Wärme ein idealer Nährboden für Bakterien und Pilze ist.

\section{Dr. med. Peter Stiefelhagen *}

. Quelle: Kirchheim-Forum Diabetes, 21. 1. 2012 in Berlin. 